\title{
NEWS FROM THE SCHOOLS
}

\author{
Department of Information and Library Studies, Faculty of Information, University \\ College of Wales Aberystwyth
}

\section{Health information activities}

The Department of Information and Library Studies (DILS) is the major department within the new Faculty of Information Studies at UCW Aberystwyth. DILS has an established international reputation in information management, text handling, database applications and information retrieval. It has the largest number of students working at postgraduate level of any department within UCW.

The DILS expertise centres upon the design, application and evaluation of information systems, from analysis of user requirements and information flows through to the monitoring and evaluation of implemented systems.

DILS has targeted health information as a priority area in its development plan. For several years it has offered courses for information professionals, and graduates of the department hold a variety of posts in health care. The range of activities in health information is expanding rapidly. Current research includes two-year funding for an examination of the processes of analyzing and determining the information requirements of health professionals. There are some grounds for believing that techniques currently applied are not fully adequate for the analysis of user needs in health care. A particular emphasis of the research is to assess the transferability of techniques for analysis of information requirements between different groups of professionals, with an emphasis on groups as yet under-researched.

A separate project, in collaboration with the Health Promotion Authority for Wales, involves three phases. Firstly, an examination of the information needs and information flows involving health promotion officers; secondly, the establishment of statistical and bibliographic databases relevant to those needs; and, thirdly, an evaluation of the delivery of information from the system to remote health promotion units. The department is responsible for Phases 1 and 3 and the Health Promotion Authority, using commercial sponsorship, for Phase 2.

The department has undertaken research in information retrieval over a period of several years. It has particular experience in the area of text retrieval software and software to facilitate online interaction for end-users. Earlier work was undertaken in these directions for the European Space Agency. New projects under discussion include the logging of CD-ROM database transactions in medicine to evaluate the search behaviour of clinicians; research into the continuing education needs of information professionals in health care; and assessment of the patient care implications of information supplied by NHS libraries. 
DILS has a strong vocational slant in its taught courses in health information and through its programme of short courses. The senior lecturer responsible for health information teaching and research is John Hepworth, who has undertaken consultancies and provided short courses for a variety of health care organizations.

Current initiatives include the introduction of a new distance learning masters course for graduates already employed or who seek employment in health information (see News section).

Further information is available from:

John B. Hepworth

Department of Information and Library Studies

University College of Wales Aberystwyth

Llanbadarn Fawr

Aberystwyth

Dyfed SY23 3AS

Wales, UK

\section{Lehrinstitut für Dokumentation, Frankfurt, FRG}

\section{Continuing education and training of documentation practitioners}

Professionals in the field of information and documentation (I\&D) in the Federal Republic of Germany come typically from different occupational branches. In 1988 it was estimated that only $10-20 \%$ of this group received their first vocational training in the I\&D profession. I\&D professionals have traditionally had previous experience as experts in other fields. Recently, an increasing number of people trained to be I\&D professionals have come from the sciences. They recognize $I \& D$ as a promising addition to their studies, an addition that offers them new perspectives for their careers, and an increasing number of people feel that the field of I\&D can be a way out of impending or existing unemployment. Common to all late entrants is that they start their new positions with much expert knowledge in their special subjects but often poor I\&D knowledge.

In larger documentation institutions, beginners are usually trained by experienced colleagues. But this involves the danger of a rather one-sided qualification. In smaller institutions, however, one has to find or develop the methods needed for one's tasks by oneself - under conditions which are hardly satisfactory. A third way would be to provide continuing training in I\&D. Whichever method or combination of methods is chosen, two critical risks are involved:

(1) knowledge of the documentation process is only partly acquired; and

(2) only those techniques and methods are learned which are needed or practised in a particular organization.

As a result, I\&D professionals often lack the theoretical background and qualifications which they need in their job, with its particular working situation and needs. And often the result is that their own and their colleagues' skills and knowledge - and with them the working methods established in a documentation 
agency-cannot reach the level that is possible in theory and practice. The gap between what is practised and what is really possible widens when you take into account the improvements opened up by the introduction and development of computers.

Though some progress has been made, there still is not much difference between the situation described above and the situation more than 20 years ago when the Lehrinstitut für Dokumentation (LID) (School for Documentation) was founded by the Deutsche Gesellschaft für Dokumentation (DGD) (German Society for Documentation). The main interest still today is to create conditions which will improve the work and results of German I\&D institutions. For this reason LID trains people working in practical documentation in theoretical and practical subject areas, independent of products and producers. This is done by a variety of courses, each of which is keyed to special target groups, their qualifications and their needs.

The aims of LID

LID is part of the German Society for Documentation and at present has six full-time staff members and about 50 external lecturers from all sectors of the I\&D profession. The school is located in the centre of Frankfurt.

The task of LID, the training of I\&D specialists, is carried out on three levels:

(1) Basic knowledge. As documentation is needed in all disciplines, LID wants its students to acquire a comprehensive knowledge of the procedures and methods which underlie documentation in all branches of science, technology, industry and administration.

(2) Practical knowledge. The requirements resulting from the current developments in documentation have to be met by documentation practitioners. Therefore staff members of documentation departments should obtain an application-oriented knowledge they can use in their daily work.

(3) Innovation and future developments. Latest developments marked especially by the influence of modern information technology are presented. It is the aim of LID to make the results of research and development referring to application situations available to the documentation professional and to give a survey of actual and possible developments.

\section{Priorities of LID activities}

Besides the training of documentation assistants, for which LID functions as a kind of para-professional school, the LID courses concentrate mainly on the following subject areas:

- In-service training: people with a university degree in any subject and working in practical I\&D settings are trained to become scientific documentalists in a 13-week course spread over one year.

- Continuing education and knowledge updating: the LID programme offers about 25 seminars per year to information workers from the whole of the I\&D profession. In these seminars, which concentrate on the latest methods and prob- 
lems in the field of information and documentation, participants can obtain theoretical and application-oriented knowledge. Thus access to this field of activity is given to practising information professionals as well to those who are new to the profession and who do not have the opportunity to follow a comprehensive continuing education course.

\section{In-service training}

The conception of the in-service training is directly related to the educational situation described as typical of the field of I\&D. LID offers an annual course for scientific documentalists to this group of late entrants as part of in-service training.

Participation in this course requires a university degree as well as practical documentation experience of at least one year. Each year in late autumn, 24 participants are selected out of usually 60 to 80 applicants. Applicants are chosen with an eye to representing a wide range of activities characteristic of documentation. This diversity is a basic requirement for a quick and efficient classification and realization of knowledge. Besides, a comparable level of basic knowledge among course participants ensures a common basis for learning and discussion.

The programme has four subject units, which reflect the essential aspects of the documentation process. These are:

(1) Design of information systems: structuring data exemplified by existing methods of literature documentation; standardizing field contents; implementing a draft database as a database management and information retrieval system; computeraided protection of data integrity; data interchange formats.

(2) Representation of knowledge: terminological and linguistic fundamentals; types and functions of documentary languages; indexing, abstracting and automatic indexing as methods of subject analysis; computer-aided construction and maintenance of terminology systems (thesauri, classifications, etc.).

(3) Using online databases: survey of the online market; search strategies; retrieval languages; communication software; processing the results of online searches; information networks.

(4) Information management and information policies: design and organization of I\&D centres; investigation of needs and user behaviour; information services and their efficiency; dissemination of information in organizations; legal aspects in the field of I\&D; structure of and trends in information science and practice.

One characteristic of the curriculum is its flexibility in responding quickly and without any bureaucratic impediments to changing information needs related to new technologies and methods. The instruction units are closely connected in their contents and methods, thus allowing the different parts of the documentation process to be represented by example. This conception is realized by LID's full-time lecturers. Guest lecturers explain and illustrate professional experience by examples.

The concept of courses lasting one year has proved to be an attractive and successful one, and not only for people working in practical documentation. An increasing number of potential newcomers and late entrants in the field of I\&D see a chance of obtaining a wide-ranging qualification by participating in the annual course for scientific documentalists. They have normally complied with the require- 
ments needed for their participation by following a period of practical training in media archives or I\&D centres.

Interest in the courses, which has manifested itself in an increasing number of applicants, has coincided - as mentioned above-with an increase in the number of unemployed academics who see new chances for their careers in the field of I\&D. This was the situation when, at the beginning of the 1980s, LID was asked by the employment office to organize additional, closed courses especially for this group of people.

In these retraining courses, similar to the annual courses for scientific documentalists, the theoretical training takes place at LID. Practical knowledge in the field of I\&D in this case is obtained in qualified and widespread field courses in I\&D placements. Thus retraining offers prospects not only for social scientists and people with a degree in the humanities, but also for chemists and biologists and in general for those professions which have been increasingly affected by the unemployment of academics during recent years.

The I\&D departments of public broadcasting stations have been particularly active in the arrangement of these retraining courses. They have a wide range of different facilities (archives for media, film, sound and pictures, as well as libraries) which cover a broad spectrum of I\&D activities. In this way they offer a particularly attractive and broad training ground for occupations outside the media.

In cooperation with the public broadcasting station Südwestfunk in Baden-Baden, LID has made a successful effort to integrate the handicapped into the occupational field of information and documentation. This has been achieved by retraining activities supported by the employment office as well as by the annual courses for scientific documentalists. The successful training of blind people for the profession of broadcasting documentalists not only offers a chance for the individual, but also promises the integration of this group into I\&D-related continuing education. At the end of 1988 this development led to the founding of the Dokumentarisches Institut in der Stiftung Blindenanstalt (Documentation Institute in the Foundation for the Blind). This institution serves the visually handicapped during their continuing education. Ongoing research projects offer further access to knowledge resources for blind and visually handicapped people by means of documentational methods.

\section{Retraining and knowledge updating}

The above-described situation for obtaining qualifications in the field of I\&D also has a profound influence on the requirements in the sector of retraining. The usual task of making new methods and techniques known to information workers by offering further training courses has to serve other target groups as well, especially newcomers and late entrants in the field who are not able to participate in courses of continuing education while working. Taking part in retraining seminars is often the only way for them to acquire the knowledge required for their work. It is essential for participants to acquire these capabilities and skills as soon as possible.

With regard to this aim, LID has divided its programme of retraining courses into subject-related and target group-related courses. LID also helps to organize regional retraining seminars and it offers in-house seminars for institutions and businesses. 
An important characteristic of LID courses is their neutrality as regards products and producers. Being neutral makes it possible to objectively evaluate available programmes and procedures and their problem solving capabilities in the context of today's I\&D tasks.

Programmes range across special subject areas and situations of application based on the lecturers' experience and knowledge.

\section{Subject-related seminars}

The rapid technical changes in the field of I\&D require that the full-time staff of I $\& D$ centres show a constant readiness to learn-the often quoted 'lifelong learning.' This can only be achieved if these people are highly motivated and have a desire to learn and if a programme of continuing education courses tailored to their needs is available.

The subject-related LID seminars with their broad programme are in principle open to everyone. They aim to give information professionals the chance to adapt themselves to changing occupational requirements. This is done in short two- or three-day courses. In this effort the following priorities are set up:

- Online databases (line D), e.g. information retrieval in data bases; downloading; converting of retrieved data for storage in in-house databases.

- Content analysis (line I), e.g. construction and maintenance of thesauri with personal computers; methods of content analysis.

- Optical memories (line S), e.g. use of CD-ROM systems; application characteristics of WORM memories and erasable disks for archivation of documents; implementation of CD-ROM systems.

- I\&D applications of microcomputers (line $M$ ), e.g. information retrieval software for personal computers; local area networks (LANs) vs. UNIX systems; documentation and modern text processing.

- Questions related to librarianship (line B), e.g. workstations in special libraries; comparison of library systems on MS-DOS and UNIX.

- Organization of I\&D centres (line Q), e.g. establishing an I\&D centre; accounting and calculation of costs for an I\&D centre.

A special characteristic of the LID programme is the effort to take into consideration the different levels of preparation among course participants. This is achieved by offering introductory courses which take place before the main courses start. All seminars can be attended as a unit as well as separately.

Additionally, the interconnection of functions and fields of activity which in practice are often separated is dealt with as often as possible. New connections occur frequently, particularly because of the ever-increasing use of computers. Computer-aided integration of sequences of operation often receives too little attention, too late.

Beyond that, the term 'interconnection' also refers to the cooperation of the related disciplines of archives and librarianship. All three fields-often shortened to ABD (Archiv-Bibliothek-Dokumentation) - use similar methods and techniques. Therefore the need for cooperation should be obvious for the purposes of continuing education. This kind of cooperation is realized in the seminars for media archivists and documentalists. 


\section{Target group-related seminars}

Together with the Fachgruppe der Presse-, Rundfunk- und Filmarchivare im Verein deutscher Archivare (Technical Group of Press, Broadcasting and Film Archivists in the Association of German Archivists) and the Verein Deutscher Dokumentare (Association of German Documentalists), a further training programme was developed for media archivists and documentalists which deals with the focal points of documentation activities in five separate one-week seminars. Here, documentation methods and techniques are discussed and practised especially with regard to their application in the mass media. While the LID lecturers mainly impart the methodological background, the media-related aspects are presented by professionals in this field. Participants who attend all seminars of the course, which takes about two years to complete, receive a certificate which is recognized by the Technical Group.

At regular intervals, LID, in cooperation with Informationsring Kreditwirtschaft $(i k)$, organizes seminars and workshops for financial services professionals. ' $i k$ ' is an association of the I\&D departments of the major banks in West Germany and the German-speaking neighbouring countries. It wants to keep up to date with the possibilities offered by online databases in order to achieve a widespread exchange of information among its members.

\section{In-house seminars}

LID is often asked to organize seminars which cover specific needs and problems of certain I\&D centres and which can take place on the premises of these centres. Here the lecturers can respond specifically to the participants' level of knowledge and questions of immediate interest. Moreover, enabling a sufficient number of staff members to attend such an in-house seminar is more practical and financially attractive than a training seminar in Frankfurt.

\section{Regional training courses}

LID and the German Society for Documentation (DGD) cooperate in regional working groups which deal with topics relating to information and documentation and which regularly offer seminars. For the information professionals these seminars are an indispensable addition to the LID programme, because the regular LID courses can only be attended when the employer allows a temporary leave. Furthermore, travel expenses are reduced by offering regional seminars. LID's lecturers cooperate in these seminars.

\section{Cooperation and consulting}

For many years there has been close professional cooperation with the Frankfurt Library School and the School for Archivists in Marburg. In the courses of studies for the mid-level and higher civil servants at these institutions the full-time lecturers of LID, for example, offer lectures on 'Specialized information' and 'Introduction to the methods and practice of information and documentation.' Colleagues from these institutions, in turn, come to teach at LID as guest lecturers.

LID has also established good contacts with the technical colleges (Fach- 
hochschulen) of Darmstadt, Hannover, Stuttgart and Köln, and their departments which train Diplom-Dokumentare (accredited documentalists) and Diplom-Informationswirte (accredited information specialists). These contacts date back to the time when these fields of study were established, about ten years ago. At that time LID contributed the experiences of its three-year courses in which qualified documentalists were trained-a kind of training preceding the specialized education of today.

Several of LID's guest lecturers come from the technical colleges and the departments of information science at the Universities of Berlin, Constance and Saarbrücken. In this way a constant exchange of opinions and experiences between the I\&D training centres is made possible.

The cooperation with the $A R D$ broadcasting companies and especially with the Südwestfunk and the Stiftung Blindenanstalt has been explained above.

LID's teaching staff are often asked for advice in questions concerning documentation. In these situations it becomes obvious that there are few information resources independent of producers and services-now even fewer since the dissolution of the Gesellschaft für Information und Dokumentation (GID) (Society for Information and Documentation) and its quasi-successor organization, Gesellschaft für Elektronische Medien (GEM) (Society for Electronic Media). At the same time, the number of institutions that want to introduce computer-aided information processing is continually increasing. And finally, because of the fast innovation cycles in the field of hardware and software, the demand for advice is constantly and sometimes even dramatically on the increase. Thus it inevitably becomes more and more difficult for LID lecturers to deal with all the requests for advice.

Very often these inquiries request a comparative evaluation of software products for I\&D purposes. This shows a quite concrete demand for product and market analyses which systematically and as a constant service can only be met within the framework of extensive projects.

\section{Summary}

The above description of the activities of LID, its conception and aims, suggests the range of tasks in the area of continuing education for information professionals in Germany. These tasks have so far been successfully realized at LID.

To summarize, the most important characteristics of LID's courses are:

- knowledge of I\&D methods as an addition to academic training;

- in-service training instead of full-time university studies;

- orientation toward the needs of everyday documentation work;

- integration of knowledge and skills into the full process of documentation; and

- information for professionals independent of products and producers. 
For more information and details of LID activities please contact:

Lehrinstitut für Dokumentation

Westendstrasse 19

D-6000 Frankfurt am Main 1

West Germany

Tel: +4969740805

Fax: +4969752430

Achim Osswald

Lehrinstitut für Dokumentation

Frankfurt, FRG 